\title{
A Comparative Study on the Construction Model of Innovation-Type Provinces in China
}

\author{
Haochen Yang, Yuzhen Duan, Wei Song, Haiyuan Zhao \\ School of Public Affairs, University of Science and Technology of China, Hefei, China \\ Email: 785696509@qq.com
}

How to cite this paper: Yang, H. C., Duan, Y. Z., Song, W., \& Zhao, H. Y. (2018). A Comparative Study on the Construction Model of Innovation-Type Provinces in China. Current Urban Studies, 6, 223-242. https://doi.org/10.4236/cus.2018.62013

Received: January 31, 2018

Accepted: June 25, 2018

Published: June 28, 2018

Copyright () 2018 by authors and Scientific Research Publishing Inc. This work is licensed under the Creative Commons Attribution International License (CC BY 4.0).

http://creativecommons.org/licenses/by/4.0/

\begin{abstract}
At present, the development strategy and mode of our country have shifted from the traditional extensive economy to the sustainable development centering on the capability of independent innovation, the construction of innovation-type provinces in all regions has become a trend. From the perspective of major of innovation-type provinces in China, depending on the different industry, the innovation-type provinces construction can be divided into the basic modes of government-leading, technology intelligence innovation, multidimensional linkage, high-end talents, knowledge leading, technology service and so on. The study is selected six innovation-type provinces of Jiangsu, Zhejiang, Guangdong, Shaanxi, Hubei and Shandong as typical provinces to analyze and compare, summarize the similarities and differences of their policies, and on this basis put forward feasible paths for building an innovation-type province in other provinces or cities in our country.
\end{abstract}

\section{Keywords}

Innovation-Type Provinces, Typical Model, Policy Environment, Talent Accumulation

\section{Preface}

In the period of Chinese economic transforming and industrial upgrading, scientific and technological innovation has been become the new power of economic growth and social development. Every province has been transforming their patterns of development actively in order to realize their innovation-driven development and innovative national strategic goals. However, there is no mature experience about the found of innovation-oriented province (Gu \& Ying, 2008). Therefore, every province should combine their own situation to choose an appropriate path, and take real-time monitor and estimate, which require estimating the degree of innovation and progress accurately and timely, and finding the 
key points and shortcomings, then adjust and optimize the construction plans.

In February 2006, the State Council of China promulgated and implemented the Medium- and Long-Term National Science and Technology Development Program (2006-2020), and put forward that forming innovative nation is the great strategic choice for China in the future, since then, the National Development and Reform Commission and the Ministry of Science and Technology have promoted the pilot work of the innovation-type provinces construction. Each province has formulated a pilot implementation plan for the innovation-type provinces construction, or a national master plan for innovation-type provinces. On April 12th 2016, the Ministry of Science and Technology formulated the Guidelines for the Innovation-type Provinces Construction, which indicated that the innovation-type provinces construction is to accelerate the implementation of innovation-driven development strategy, and enter into the inevitable requirement of innovation-oriented country ranks in 2020. It is the inner need to cultivate and develop the new motive force and lead the new normal of economic development. It is an important support for the implementation of the overall national strategy for regional development and the promotion of regional coordinated development (Zhang \& Lin, 2006).

Innovation-type province refers to the region where the independent innovation is the basic strategy, which greatly enhances the technological innovation capability, and the innovation becomes the core driving force, and the technology plays a decisive role in economic and social development. Each province has formulated the corresponding development goal, developing focus and direction, has basically formed the unique innovation pattern, including Jiangsu Government-led Innovation Model, the Innovation Model of Zhejiang Technology, Innovation Mode of Guangdong's Multi-dimensional Linkage, Innovation Mode of training and introducing High-end talents in Shaanxi, Innovation Mode of knowledge leading in Hubei, and Innovation Mode of Shandong Technology Service, etc., according to the characteristics of the province in the process of constructing the innovative provinces (Lan \& Chen, 2015). The regional innovation capability of these provinces is at the forefront of our country, and has formed its own characteristics in the long-term development process and accumulated rich experience in development. The construction experience of innovative province with unique characteristics will provide valuable references for other regions in building an innovation-type province. So, we selected Jiangsu, Zhejiang, Guangdong, Shaanxi, Hubei and Shandong as typical provinces to analyze respectively.

\section{An Analysis of the Development Model of Innovation-Oriented Cities in China}

\subsection{Jiangsu Province: Government-Led Innovation Model}

As one of the provinces with strong innovation ability, Jiangsu Province is the model of innovation-type province in China. Jiangsu Province insists on the 
strategy of innovation-driven development, gives policy support to industry-university-research cooperation and attaches importance to the implementation of intellectual property strategy, which provides strong policy support for the construction of innovation-type province in Jiangsu Province (as shown in the Figure 1). The unique features of Jiangsu Province in the construction of innovation-type province are:

First, the strategy of innovation-driven development is insisted. Jiangsu Province has taken the lead in taking the innovation-driven strategy as the core strategy of economic and social development in exploring and constructing innovation-type provinces. In the early 2006, Jiangsu took the lead in making a major decision to build an innovation-type province to 2015. At present, as the first pilot province of innovation in China, Jiangsu has ranked in the forefront of regional innovation capability in recent years and made significant progress in building an innovative province. In March 30th 2016, Jiangsu Government held a press conference to issue the 13th Five-Year Plan outline for the National Economic and Social Development of Jiangsu Province, pointing out that the strategy of innovation-driven development should be implemented. The core position of innovation is strengthened further in the overall development, and ran innovation in the whole process of Economic and Social Development to vigorously promote the theoretical, institutional, technological, and cultural innovation, etc., highlight the innovation of industry technology, inspire innovation and entrepreneurial vitality of the whole society, actively cultivate the New Kinetic Energy of Economic Development and improve the traditional Kinetic Energy, accelerate the formation of an economic system with innovation as the main guide and support of the economic system and development mode, and take a new development way of the higher quality, better benefit, better structure and full release of advantages (Xu, 2013).

Second, pay attention to the cooperation of industry-university-research, and give policy support. In order to promote the deepening of the cooperation of industry-university-research, and realize the transformation and industrialization of technological achievements, the state has formulated corresponding policies and regulations, Jiangsu Province and cities (counties) have also formulated relevant policies and measures according to their own conditions, foundations and characteristics, and effectively promoted the in-depth cooperation of industry-university-research in Jiangsu Province(as shown in the Table 1). At present, there are more than ten public network platforms serving for the cooperation of industry-university-research in Jiangsu. These platform functions have its own emphasis, which has formed the network platform system for the cooperation of industry-university-research in Jiangsu Province. Moreover, Jiangsu Province holds a "Exhibition Fair for the achievements of industry-university-research cooperation" to Domestic. "International Conference on the cooperation of industry-university-research and Transnational Technology transfer", and Exhibition Fair of China (Nanjing) International Software products have become a unique 


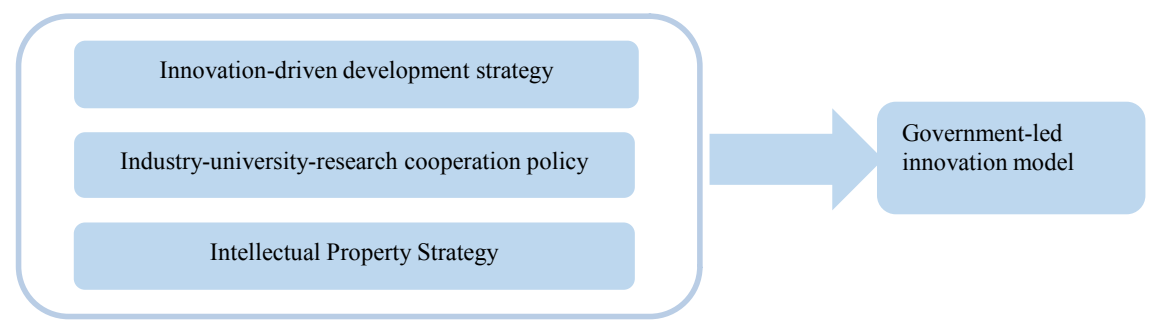

Figure 1. Jiangsu Government-led innovation model.

Table 1. Major laws and policies of the state, Jiangsu and cities (counties) to promote the cooperation of industry-university-research in recent years.

\begin{tabular}{|c|c|}
\hline Level & Major laws and policies \\
\hline National level & $\begin{array}{l}\text { Technical Cooperation Law, Patent Law, Law on Promoting the } \\
\text { Transformation of Technological Achievement of the People's Republic } \\
\text { of China, Decision on Speeding up the Cultivation and Development of } \\
\text { Strategic Emerging Industries, Measures to Promote the Construction } \\
\text { and Development of Strategic Alliance for Industrial Technological } \\
\text { Innovation ( trial implementation), Opinions on Mobilization of Sci-tech } \\
\text { Workers to Serve Enterprises }\end{array}$ \\
\hline Provincial level & $\begin{array}{l}\text { Measures for the Implementation of the Introduction Plan of High-level } \\
\text { Entrepreneurship Innovation Talents in Jiangsu Province, } \\
\text { Measures of Special Fund management for Transformation of } \\
\text { Technological Achievements in Jiangsu ( trial implementation) } \\
\text { Several opinions on speeding up the Development of High-tech } \\
\text { Industrial Development Park } \\
\text { Interim Management Measures of Special Fund for Risk Compensation } \\
\text { of Technological Achievements Transformation in Jiangsu }\end{array}$ \\
\hline Cities (counties) level & $\begin{array}{l}\text { Several Regulations on Promoting the Transformation and } \\
\text { Industrialization of High-tech Achievements in Nantong City } \\
\text { Interim measures on strengthening the Administration of Appraisal of } \\
\text { technological achievements of Suzhou Science and Technology } \\
\text { Commission } \\
\text { Several Views on Strengthening Cooperation of } \\
\text { Industry-university-research in Changzhou City } \\
\text { Opinions on encouraging and supporting Technological Innovation in } \\
\text { Yancheng Dafeng City }\end{array}$ \\
\hline
\end{tabular}

Source: according to the result.

brand of cooperation of industry-university-research to foreign countries every two years.

Jiangsu Province supports the cooperation of industry-university-research by the fiscal policy. Jiangsu Province has the research funding departments of the Development and Reform Commission, the Department of Science and Technology, and the Department of Education (or Bureau), etc. These departments have natural science funds, special funds for the transformation of scientific and technological achievements, high-tech industrialization projects, special funds projects for the transformation of scientific and technological achievements, and high-tech industrialization projects, patent implementation program projects 
and technology progress awards, etc., which promote the cooperation of industry-university-research. Moreover, Suzhou, Wuxi and Taizhou have also adopted tax support policies, such as Suzhou's pre-tax 150\% deduction of research and development fees for the pharmaceutical and biotechnology enterprises, Taizhou prescribes scientific research institutions and other scientific and technological service enterprises to be set up in China Medical City, the local portion of business tax retained within 1 year and the local portion of enterprise income tax within 2 years are awarded to the unit in full as scientific and technological support from the date of operation.

In addition, Jiangsu Province also implements the policy of attracting talents to promote cooperation of industry-university-research. It mainly provides financial subsidies by introducing talents, facilitates the transfer, implementation of preferential policies in the related procedures of personnel relations, various types of insurance, professional title, etc. Meanwhile, many places also have set special awards for outstanding talents and outstanding contributors in the cooperation of industry-university-research. Some localities with abundant financial resources have also set special funds for the development of talents. However, there is still a lack of strong and stable support and encouragement policies for the relevant personnel training. Moreover, Jiangsu Province has also begun to explore and use the evaluation, assessment and operating subsidies to promote the establishment of an application-oriented scientific research evaluation system in colleges and universities, and encourage researchers to enter the industrial front line.

Third, rely on the implementation of the innovation-type provinces construction with intellectual property strategic escort. In 2009, Jiangsu Government adopted the outline of the intellectual property Strategy of Jiangsu Province to put forward the implementation of the intellectual property Strategy and vigorously develop and utilize the advantage of talents, promote the adjustment of economic structure and transformation of development ways, promote the self-dependent innovation and innovation-type construction, establish the consciousness of knowledge Resources for Rule of Law, and accelerate to promote the creation, use, protection and management capability of intellectual property rights. It is of great strategic significance to give full play to the good image of Jiangsu in technology and education, and promote the market competitiveness of enterprises and the core competitiveness of regional economy, realizing the leapfrogging from "Jiangsu processing" to "Jiangsu creation".

\subsection{Zhejiang Province: Innovation Mode of Technology Intellectual Creation}

The innovation-type provinces construction of Zhejiang was originated several opinions on accelerating to promote the independent innovation capability to construct the innovation-type provinces and strong technology province in 2006. As the most dynamic province of private economy in China, Zhejiang 
Province carries out new high-tech enterprises cultivation action, constructs the innovation method public service platform, vigorously enhances technology the enhancement function to the enterprise scale and competitiveness by cultivating small and medium-sized technology-based enterprise, which to be unique in the innovation-type construction, the specific performance are (Yang et al., 2006).

First, actively cultivate small and medium-sized scientific and technological enterprises. Technology-based medium-sized enterprises are the main body of technological innovation and the most dynamic and potential enterprises. In 2013, the Zhejiang Science and Technology Department issued the "Special Action Plan for the cultivation of small and Medium-sized Science and Technology Enterprises", which strongly encouraged scientific and technological personnel to set up scientific and technological enterprises and build incubators for them. For example, Provincial Technology Business Incubators or University Science Parks are given 2 million yuan financial assistance, National Technology Business Incubators or University Science Parks are given 3 million yuan financial assistance, the funding is mainly used for the construction of public laboratories, establishment of seed funds and venture funds, etc. We can stimulate the venture capital to invest in the science and technology small and medium-sized enterprises in the initial stage, and increase the opportunities for the small and medium-sized technological enterprises to obtain the venture capital by guiding role of the policy to guide the funds. Focusing on the main direction of industrial development of high-tech parks, and focusing on the high-tech small and medium-sized enterprises in high-tech parks to select a batch excellent to cultivate, introduce a batch science and technology small and medium-sized enterprises for giving key support to them.

Second, implement the cultivation of High-tech Enterprises. On the basis of selecting enterprises with better innovation foundation and great potential for development, Zhejiang Province has stepped up efforts to cultivate, encouraged enterprises to strengthen technological innovation activities, strengthened the cultivation of independent intellectual property rights of enterprises, guided enterprises to establish research and development centers, undertook various national and local scientific and technological planning projects, helped enterprises to establish cooperative relations with institutions of higher learning and scientific research institutes, and guided and promoted more enterprises to grow into high-tech enterprises as soon as possible. Intermediaries of tax, law, evaluation, consulting, and intellectual property are organized to key cultivation by selecting the best emerging and high-tech industries and other key areas of science and technology SMEs, and develop the whole process and specialized service for enterprises (Chen, 2009). The scale of new high-tech enterprises is promoted to try to cultivate many large enterprises and groups with large scale, core technology and their own brands, and have a voice in the industry, so that they become the leading leaders in the development of high-tech enterprises in our province. 
High-tech business incubator, university science park and all kinds of innovation, R \& D base are vigorously developed to establish and perfect scientific and technological intermediary service system by relying on various innovative service platforms, such as high-tech park above provincial level, distinctive industrial base, high-tech business incubator, university science park, technology transformation institution, etc., security of conditions and effective services are provided to the growth and development of high-tech enterprises. Many high-tech enterprises have been increasing and formed a large scale in Zhejiang Province at the period of 2011-2015 (as shown in the Figure 2).

Third, set the public service platform for the innovative methods. According to the characteristics of the scattered and difficult concentration of innovation resources in Zhejiang Province, the construction can be divided into blocks and types in the construction of public service platform of innovation methods. At first, 4 platforms of innovative methods of technological literature resources co-construction and sharing platform, cooperative sharing platform for large instrument and equipment, laboratory animal public service platform, and technology achievement sharing service platform were set. Later, four basic condition platforms, such as "biotechnology resource sharing platform", "scientific data sharing platform", "intellectual property public service platform" and "standardized technology service platform" (as shown in the Figure 3), were set. At the same time, 22 Industry Science and Technology Innovation platforms and 5 regional STI platforms were set.

\subsection{Guangdong Province: The Innovative Mode of Multi-Dimensional Linkage}

Guangdong Province is the bridgehead of China's opening to the outside world, innovation soil is more fertile. Guangdong provides a good environment for innovation-driven, pays attention to the construction of service platform for innovation methods, and constructs multi-dimensional independent innovation fulcrum (Jiang \& Zheng, 2013) (as shown in the Figure 4). The way to innovation has its distinctive characteristics, which are embodied in:

First, attach great importance to innovation-driven, and provide a good environment. Provincial Party Committee and provincial government of Guangdong attach great importance to the importance and urgency of accelerating innovation-driven development, and emphasize that the implementation of innovation-driven development strategy shall be taken as the overall grasp and core strategy to create new advantages of innovation-driven development (Duan et al., 2016). Guangdong Provincial Government also launched the first document-Several policy opinions on accelerating technological innovation in 2015. From the aspects of innovation voucher subsidy, high-tech business incubator construction land and financial subsidy, as well as the income from the transformation of technological achievements and the secure residence of talents to put forward many major innovation policies that have been first explored and 


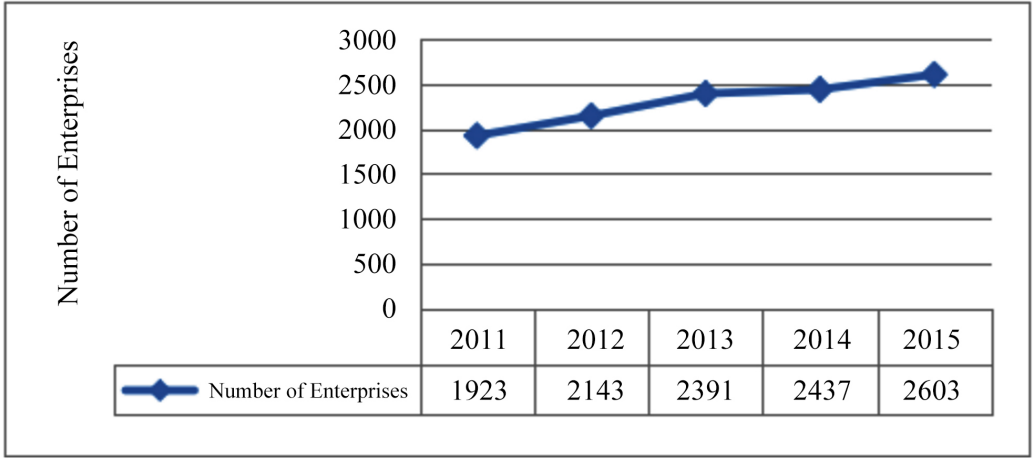

Figure 2. Change in quantity figure of high-tech enterprises in Zhejiang Province between 2011-2015. Source: according to the Statistical Yearbook of Zhejiang Province in 2011-2015.

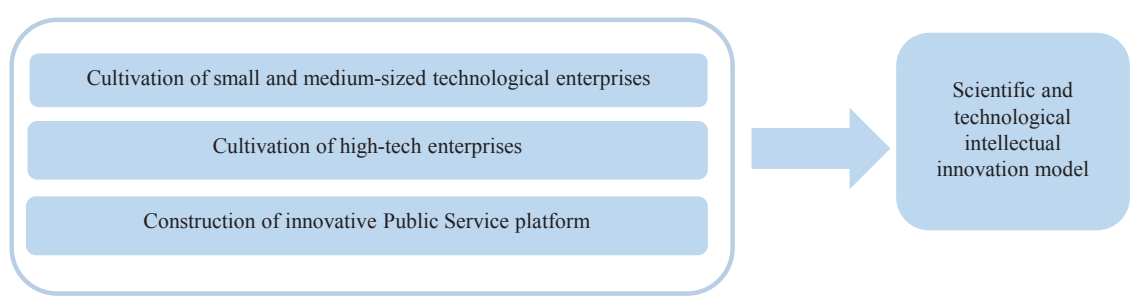

Figure 3. Innovation mode of science and technology intelligence in Zhejiang Province.

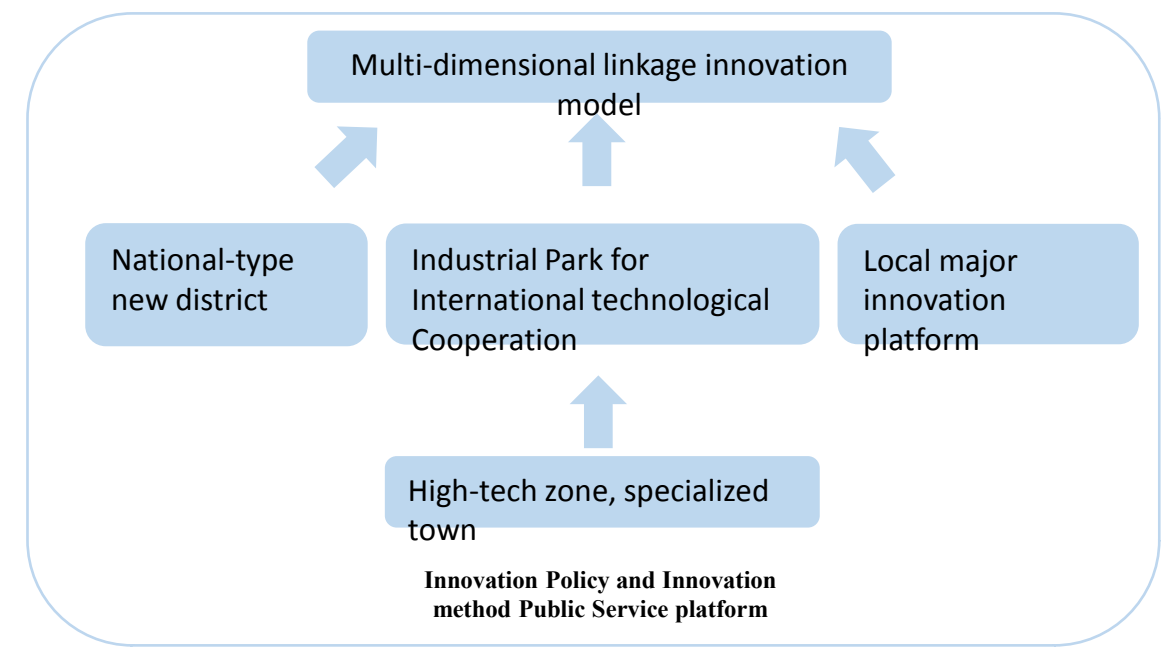

Figure 4. The innovative mode of multi-dimensional Linkage in Guangdong Province.

implemented in China. These fully reflect that Guangdong has created a good policy environment for the implementation of innovation-driven initiative and creation of a good policy environment in innovation.

Second, pay attention to the construction of public service platform with innovative methods. Proceed from many respects to advance all-round. First of all, it has strengthened the financial input of the innovation method public service platform, and perfected the infrastructure construction of the innovation method public service platform. Guangdong has set a special fund for the develop- 
ment of innovative methods, with emphasis on strengthening the construction of public service platforms for innovative methods, such as R \& D institution, business incubator, and VC service center to provide technical guidance for enterprises in the process of promoting the application of innovative methods $(\mathrm{Wu}, 2014)$. Then, accelerate the construction of information platforms for innovative methods and public services. Under the leadership of Guangdong Government and driven by the market, various kinds of information databases based on the Internet shall be developed, and the interconnection and integration of related databases of various innovative public service platforms shall be strengthened. And next, focus on innovative methods of public service communication platform construction. Conference on results of innovative methods with significant impact is conducted to focus on the display, exchange and trading of scientific and technological achievements. Finally, it has cultivated the innovation method public service platform innovation team. Since the implementation of the plan of introducing innovative scientific research teams and leading talents in Guangdong Province, the mechanism of "introducing talents by talents and cultivating talents by talents" has been formed, which has played a very good role in demonstration and agglomeration.

Third, structure multi-dimensional independent innovation fulcrum. Guangdong has focused on promoting the reform of the technology system, deepening the cooperation of industry-university-research of provincial ministry and institute and international technology, relying on the two major innovative carriers of high-tech zones and specialized towns, to vigorously develop strategic emerging industries and technology services such as high-tech industries and LED, accelerate the pace of transformation and upgrading of traditional industries, and three new state-level areas, Nansha, Shenzhen, and Hengqin, Zhuhai, Zhongxin (Guangzhou) Knowledge City, China and Germany (Jieyang) Metallic Ecological City, Sino-German (Foshan) Industrial Service area, China and Israel (Dongguan) Industrial Park for International Scientific and technological Cooperation (Lu et al., 2008), and Dongguan Cross-Strait Biotechnology Industry Cooperation Base, have been formed. Focus on local innovation platforms of supporting Zhuhai Aeronautical Industry Park, and Zhanjiang Southern Sea Valley, forming numerous independent innovation fulcrum.

\subsection{Shaanxi Province: Innovative Mode of Training and Introducing High-End Talents}

Shaanxi Province is rich in higher education resources, and ranks among the top in the country. Shaanxi Province is playing a great role in promoting innovative provinces by building the highland of innovative talents, organizing scientific and technological problems, integrating resources and developing clusters (You et al., 2011). The innovation and development of Shaanxi Province has its unique features (as shown in the Figure 5), which are:

First, create innovate talents model, and help to build innovation-type 


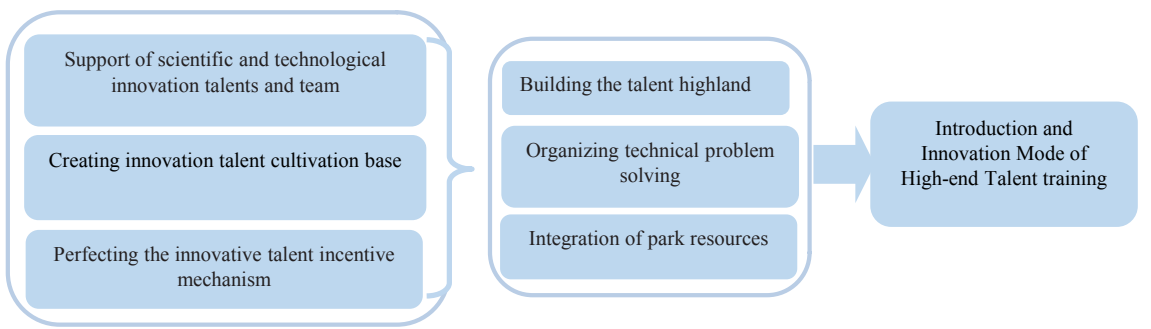

Figure 5. Innovative Mode of training and introducing high-end talents in Shaanxi Province.

province. The Opinions on strengthening the Construction of High level innovative and pioneering talents is introduced by Shaanxi Province, which encourage high-level talents to focus on scientific research and innovation to strengthen the protection and encouragement of high-level innovative and entrepreneurial talents, implement the system of "the allowance for Sanqing talents, the allowance for academicians of Shaanxi will be increased from 30,000 yuan per person per annum to 60,000 yuan per person per year, and the newly elected academicians of the Chinese Academy of Sciences and the Chinese Academy of Engineering are awarded 100,000 yuan. Meanwhile, Shaanxi Province also set up a "Shaanxi Province academicians expert workstation". Since the establishment of Shaanxi Province academicians expert workstation, the role of academician experts has been brought into full play to promote the goal of scientific and technological innovation in enterprises and help enterprises to cultivate scientific research teams, carry out joint tackling key problems around major key technical problems, promote the transformation and industrialization of technological achievements, and promote the close integration of industry-university-research, and co-construct personnel training base. Moreover, Shaanxi has also carried out a series of activities, such as "academicians, experts, Shaanxi travel", and organized academicians and experts to carry out advisory services and study tours at the grass-roots level, it provides a platform for academicians to understand the basic level and familiarize themselves with the situation of the province. Meanwhile, the academicians can also go deep into the grass-roots to release the scientific and technological potential and contribute wisdom and strength to the people of Sanqin.

In the field of scientific and technological innovation, Shaanxi Province focuses on selecting, training and supporting young and middle-aged scientific and technological innovation talents from esearch and development team of major scientific research projects and scientific achievements at the national lev$\mathrm{el}$ and at the provincial and ministerial levels. In the field of scientific and technological innovation and entrepreneurship, Shaanxi Province focuses on supporting outstanding entrepreneurial talents using independent intellectual property rights or core technological innovation and entrepreneurship.

In the technical innovation team aspect, rely on the national and provincial major scientific research projects, key projects and major construction projects 
to set innovation team in key areas. In the training of young science and technology new stars aspect, by the ways of project funding for activities such as scientific research, technology development, and product transformation to cultivate scientific and technological leaders, enter major talent projects at the national and provincial levels as soon as possible, and provide technology and talent reserves for the construction of strong western provinces.

In building innovative talent training base, Shaanxi shall focus on supporting national high-tech zones (base), scientific research institutes and colleges and universities to build innovative talent training demonstration base. Meanwhile, Shaanxi Province has continuously improved the incentive mechanism for scientific and technological talents, awarded outstanding entrepreneurs in scientific and technological innovation, highlighted the contribution of experts and leaders in science and technology, and strengthened the creation, application, protection and management of intellectual property rights, implemented the laws and regulations on the participation of technical elements in income distribution (He, 2007). Shaanxi Province's “13th Five-Year Plan” highlights the guidance of "high precision and lack of talents" and promotes the way of "bringing talents with projects", and builds a batch innovative talents training demonstration base. By 2020, the total talent resources will reach to 5.55 million. Shaanxi actively cultivates entrepreneurship, and cultivates a batch enterprise leaders with international vision and familiar with the operation of capital, improves the mechanism of talent flow and allocation, and guides and encourages talent to flow to the grass-roots level, hardship areas and positions, and implements more open policies of introducing innovative talent.

Second, organize technology to tackle key problems and promote industrial transformation and upgrading. In order to accelerate industrial transformation and upgrading, Shaanxi science and technology department has condensed out 26 key industries innovation chain and more than 260 key technological innovation points to organize technical problem solving in the whole society, and organize and implement a batch resource conversion technology projects, recycling economy technical projects, major technical equipment and characteristic superiority equipment projects, such as the" kerosene co-smelting" project of Yanchang Group, "clean energy vehicle" project of Shanqi in the major special ways of enterprise association. Meanwhile, in the fields of 3D printing, cloud computing, large data to organize the strategic alliance of industrial technology innovation, advanced deployment of advanced technologies and key common technologies to tackle key scientific and technological problems. New, high-end service development of cultural creativity and design services are promoted by the implementation of special programs to strengthen the deep integration of technology and culture.

Third, integrate park resources, and cluster development. Shaanxi Province has also achieved remarkable results in accelerating the innovation and development of park bases, building innovative cities and counties, and optimizing 
the environment for scientific and technological innovation, which has attracted many talents to land and develop. The Shaanxi Science and Technology Department proposes to establish Guanzhong National pilot Zone for Independent Innovation and Comprehensive Reform with Xi'an Hi-tech Industrial Development Zone as the core to strive for the relevant preferential policies, so as to realize the agglomeration and integration of the superior resources of the five state-level high-tech zones and all kinds of industrial parks in the Guanzhong District, build a demonstration Belt for the Development of National High-tech clusters, and support the construction of innovative provinces.

\subsection{Hubei Province: Knowledge-Based Innovation Model}

Wuhan, the capital of Hubei Province, has become a model of innovative cities in China with its Optical Valley Innovation Model guided by its knowledge. The innovative development of the provincial capital Wuhan, has also led to the innovation development of the whole province.

Hubei Province encourages scientific and technological innovation, gives play to the demonstration role of high-tech parks, and attaches importance to the practice of creating new talent team , and put it on a unique way of innovation (as shown in the Figure 6), which are:

First, encourage scientific and technological innovation. Hubei Province has a large number of universities, scientific research institutions, design institutes, defence-related science and technology units, rich scientific and technological knowledge and talents, strong scientific and technological competitiveness. As of 2016, Hubei Province already has 129 universities, more than 2100 scientific research institutions, and more than 69,000 scientific and technological talents, the environment for scientific and technological innovation and entrepreneurship in Hubei Province has improved significantly. The innovation policy of "Ten rules of Science and Technology", "New Nine" in China, and scientific and technical structural reform is comprehensively and thoroughly promoted. The great transformation project of scientific and technological achievements and the Science and Technology Enterprise Entrepreneurship and cultivation Project have been launched one after another with remarkable results, and the annual turnover of technology contracts has maintained an annual increase of more than $50 \%$ in the province, thus maintaining the first place in the central and western regions by great advantage and leaping to the second place in the country, which exceeding 83 billion yuan. Hubei further increases the incentives for science and technology awards, highlights the incentive and guiding role of scientific and technological awards, and fully mobilizes the enthusiasm and creativity of scientific and technological personnel. A series of policy documents, such as the interim measures on strengthening the Application and Protection of Patent creation, interim measures on strengthening the Application and Protection of Patent creation, the intellectual property strategy implementation promotion plan of Hubei Province, and outline of the action plan for intellectual 


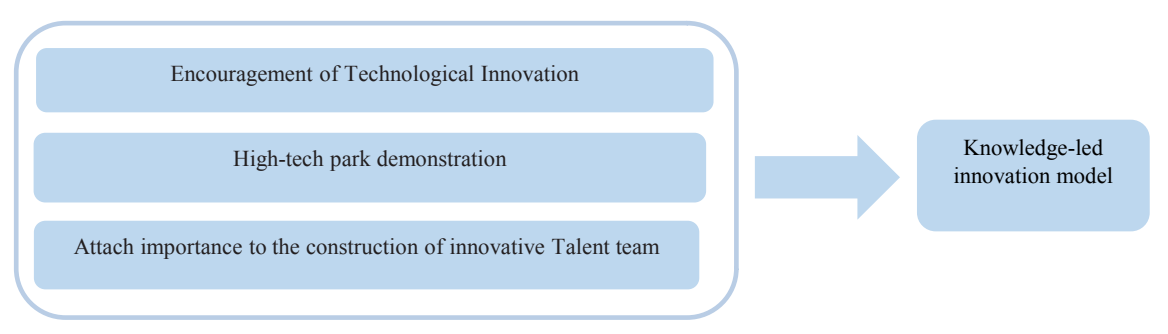

Figure 6. Innovation Mode of knowledge-based in Hubei Province.

property protection of Hubei Province, have been issued successively to create a good policy environment and continuously promote the construction of innovative provinces.

Second, the demonstration effect of high-tech park is remarkable. Wuhan Donghu High-tech Zone has unique geographical advantages, convenient transportation and early industrial pattern, meanwhile, it has become the second largest intelligence intensive area in the country because of universities converges place and high-end talent concentration, and has also rapidly grown into a leader in the early regional new technology development zones in the same batch of the country. In addition, multi-city states of Xiangyang, Yichang, Xiaogan, and Xiantao are connected with the establishment of high-tech industrial parks, and new scientific and technological achievements continuously are born in the guidance of national strategy and provincial layout. By 2020, it is expected that the proportion of the output value of high-tech industries to the total industrial output value above the scale will reach more than $70 \%$, three strategic emerging industries of information technology, life health and intelligent manufacturing will account for more than $70 \%$ of the high and new technology industries, and the proportion of private high-tech enterprises will also exceed $70 \%$. The high technology industry patent application quantity was increased in Hubei at 2011-2015 in terms of patent applications (as shown in the Figure 7).

Third, attach importance to the construction of innovative talents. Hubei Province organizes and implements "High-end talents in Hubei Province", the aim of the plan is to select a batch young and middle-aged scientific and technological talents with outstanding innovation ability and potential for innovation, by 5 - 10 years of continuous support, to create a world-class, domestic leading level of top talent team, enhance the competitive power of technology talents in the province's superiority field, and promote the transformation of Hubei Province from a large province of talented people to a strong province of talents (Jiang, 2010). "Five kinds of resources" is coordinated to strengthen the cultivation, introduction and use of scientific and technological talents. With science and technology as a link to strengthen the cultivation of scientific and technological talents; relying on technology awards to strengthen recognition and award for technological talents; international technological cooperation as a platform to enhance introduction of technological talents; take the innovation 
base as the carrier to condense the technology talents; relying on the investment and financing platform of technology to provide the investment and financing service for scientific and technological talents.

\subsection{Shangdong Province: The Innovation Mode of Science and Technology Service Guidance}

Shandong Province, is located in East China, has a good regional position. Shangdong vigorously builds technology intermediary service talent team for support to construct the service system of technology intermediary, promote the improvement of the scientific and technological level of the province and accelerate innovation-type province construction by creating a good policy environment for technology intermediary service (as shown in the Figure 8). The unique features of the construction of innovative provinces in Shandong Province are as follows:

First, the policy of technology intermediary service has been perfected with each passing day, and a good innovation environment has been formed. Since China's reform and opening up, Shandong Province has issued more than 50 scientific and technological innovation policies and regulations, such as the policy documents of "regulations on promoting the transformation of scientific and technological achievements of Shandong", "regulations of Shandong Province

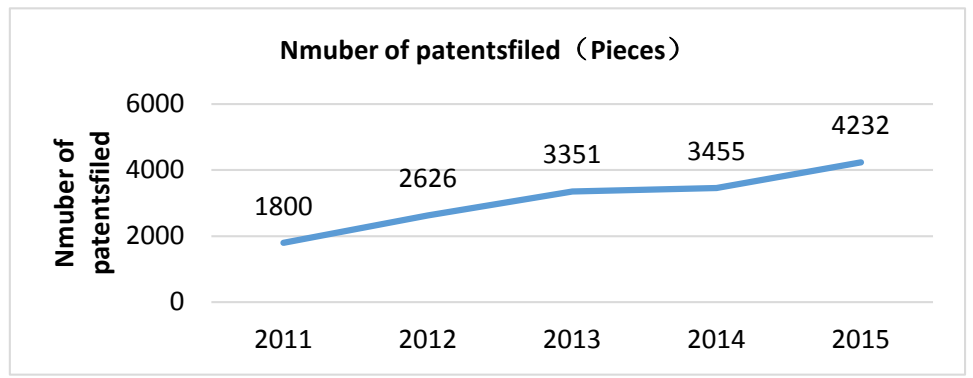

Figure 7. Change of patent application quantity of high technology industry in 2011-2015. Source: according to the Statistical Yearbook of Hubei Province 2011-2015.

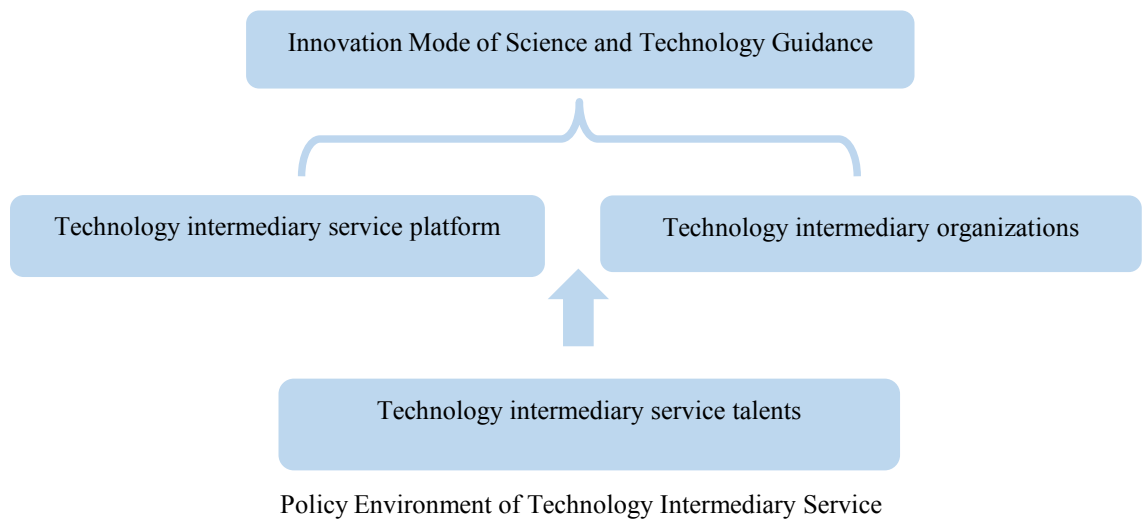

Figure 8. Innovation mode of science and technology guidance in Shandong Province. 
on hi-tech development", "suggestions on how to give full play to the leading and supporting role of technology to promote the steady and rapid development of economy and society", and "opinions on accelerating the transformation of technological achievements and improving the independent innovation ability of enterprises (for trial implementation)", forming a huge policy system.

Second, scientific and technological intermediary service system is structured in Shangdong, which is an important part of independent innovation system and an important foundation to promote the development of industry. As a serve as a link between technology and service industry, its business content, service quality and development trend must depend on the level of economic development and comprehensive strength of technology. In 2016, Shandong Province realized GDP of 6.70082 trillion yuan, an increase of 7.6\% over the same period last year, ranking third in the country, of which the added value of the tertiary industry was 3.1669 trillion yuan, an increase of $9.3 \%$ over the same period last year. Good economic foundation and scientific and technological level have created favorable conditions for the development of science and technology service industry in Shandong Province (Shen \& Wang, 2009). Shandong Province has established more than 400 public and technical service platforms, and technology services have grown to more than 3000 around decision-making consulting, technology diffusion, achievement transformation, technology evaluation, personnel training, management consulting and so on. Shandong Province has played a role as a science and technology intermediary service in terms of promoting independent innovation, promoting the development of small and medium-sized scientific and technological enterprises and accelerating the transformation of scientific and technological achievements. Science and technology intermediary organizations, represented by productivity promotion center, entrepreneurial service organization (incubator), sci-tech consultation and evaluation institution, technology market organization, technology extension agency and science popularization agency are developing rapidly, meanwhile, introducing and establishing intermediary organizations for scientific and technological supporting services of achievement assessment, transaction, and arbitration, etc. (Peng, 2013). The establishment of these innovation platforms and scientific and technological intermediary organizations has greatly promoted the independent innovation and development of science and technology enterprises in the province, and it can be said that the intermediary service policy system of Shandong Province is relatively perfect. The employment of technology services continued to increase steadily between 2012 and 2015 in Shandong Province, indicating that the scientific and technological service industry is growing and developing rapidly in Shandong Province (As shown in the Figure 9).

Third, pay attention to science and technology intermediary service talent team construction. Science and technology intermediary service industry is a knowledge-intensive industry, its practitioners should have a deep science and technology background and master the multi-disciplinary knowledge of management, 


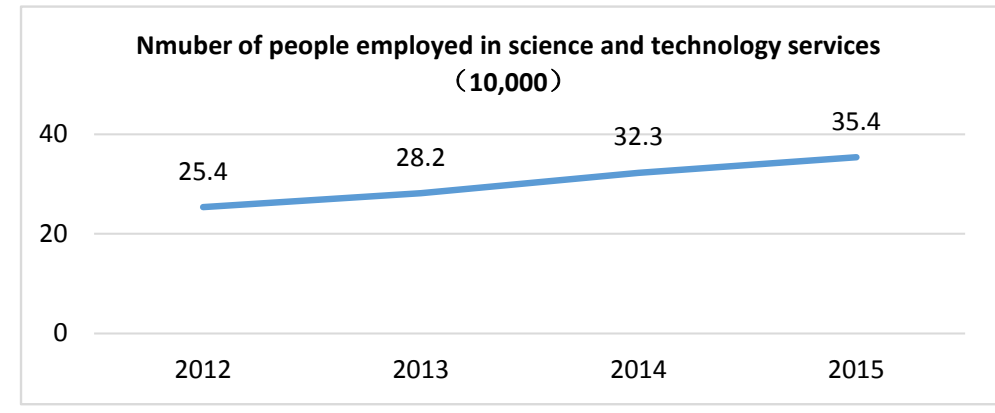

Figure 9. Changes in employed persons of science and technology service industry of Shandong Province between 2012-2015. Source: According to the Statistical Yearbook of Shandong Province 2012-2015.

economy, finance, and law, etc. Talents play an important role in the survival and development of intermediary institutions. Shandong province has introduced preferential policies to attract high-quality intermediaries and encourage experienced scientific and technical worker to engage in intermediary services. Meanwhile, through training and other ways to improve the knowledge structure and overall quality of in-service staff, and perfect their employing regime, improve the enthusiasm and creativity of staff, and vigorously develop human resources. To do a good job in constructing High-tech Patent Agent and Technical broker team, and carry out the work of Certification and Management of the Certified Consultants. Relying on the high quality staff to promote the development of technology intermediary institutions and better service for the scientific and technological innovation and economic construction in Shandong Province. In recent years, Shandong technology intermediary service personnel gradually and steadily rise. As of end of 2015, the scientific research intermediary service personnel have reached 31726, which indicates that Shandong Province has made great efforts to promote the construction of scientific and technological intermediary service personnel team. Shandong Province attaches great importance to the construction of scientific and technological intermediary service personnel team, which has greatly promoted the construction of its innovative province.

\section{Inspiration to the Innovation-Type Provinces Construction in Other Provinces and Cities of China}

The above analysis of the innovation-type provinces of Jiangsu, Zhejiang, Guangdong, Shaanxi, Hubei and Shandong shows that there are significant differences in innovation patterns among different provinces, but the mechanism of innovation development is roughly the same. The construction of innovative provinces generally adheres to the strategy of innovation-driven development, creates a good policy environment, pays attention to the development of innovative industries, accelerates the gathering of talents, and strengthens the cooperation between production, education and research in China. These practices have 
many beneficial implications for the construction of innovative provinces in other provinces and cities of China (Hu \& Liu, 2010).

\subsection{Optimizing the Innovation Policy Environment}

Attach great importance to the core strategy of innovation-oriented. Other provinces and cities in China shall learn from the experience of Jiangsu Province in adhering to the strategy of "innovation-driven development" in the construction of innovative provinces to unswervingly adhere to the strategy of "innovation-driven development", which runs through the whole process of economic and social development. In the context of deep integration into the establishment of the Yangtze River Delta economic circle and second comprehensive national science center in other provinces and cities in China, it is necessary to correctly understand the spirit of the Opinions on implementing the Strategy of Innovation-Driven Development and further accelerating the Construction of Innovation-Oriented provinces, the innovation-driven development strategy is insisted as the core strategy of constructing innovative provinces. The experience of Guangdong and Shandong to optimize the policy environment through the financial subsidies, transformation of scientific and technological achievements and promotion of scientific and technological intermediary services are imitated to carry forward the spirit of Hui-Shang, create an innovative culture with advocating innovation, tolerant of failure, and accepting. Strengthening the creation, application and protection of intellectual property to create a fair competition market environment. Other provinces and cities shall make great efforts to amplify the effect of financial investment, promote the deep combination of technology and finance, construct a diversification, multi-channel and multi-level system of scientific and technological investment, and optimize the investment and financing environment of scientific and technological innovation (Bo et al., 2013).

\subsection{Pay Attention to the Development of Innovation Industry}

The main direction of innovation is focus on the industrial development to promote the combination of technology and economy. Other provinces and cities in China have great potential in developing high-tech industries and strategic emerging industries. Therefore, we shall formulate relevant policies for supporting actively and improving the contribution rate of high-tech industries to the economy (Xu, 2013). By actively cultivating high-tech small and medium-sized enterprises and high-tech enterprises, Zhejiang Province optimizes the industrial structure, promotes" seven industries" of information, environmental protection, health, tourism, fashion, finance, high-end equipment for major breakthrough and leading development, which is the key to the supplyside structural reform in Zhejiang Province. Zhejiang Innovative Province Construction Model of "Science and Technology Intelligence Building" shall be imitated to focus on the eight leading industries and ten big and high growth in- 
dustries, and focus on the featured advantageous industries of electronic information and equipment manufacturing, define the main direction and breakthrough of scientific and technological innovation, and accelerate the construction of industrial technological innovation system by other provinces and cities in China.

\subsection{Acceleration of Talents Gathering}

Talents, as the most active factor in the construction of innovative provinces, shall attach great importance to the gathering of talents. Shaanxi Province strengthens the guarantee and encouragement of high level innovative venture talents, focuses on supporting outstanding entrepreneurial talents who use their own intellectual property rights or their core technological innovations to start their own businesses in terms of scientific and technological innovation leaders, constructs the technical innovation team, and creates innovative talent training base to gather many innovative talents for the construction of innovative provinces in Shaanxi Province. It has provided powerful intellectual support to promote the construction of talent team and help the construction of innovative provinces in Shaanxi Province. Other provinces and cities in China shall lesson from the experience of Shaanxi in introducing talents, and reform and improve the mechanism of talent training, introduction, evaluation and encouragement. Other provinces and cities in China also shall implement the plan of encouraging innovation and entrepreneurship in Anhui Province by introducing the high-level scientific and technological talents team to Anhui Province, develop the regional innovation and cooperation in other provinces with the Yangtze River Delta, the middle four corners and Zhongguancun,etc., support enterprises and scientific research institutions in other provinces and cities in China to go out and set up research and development institutions, cultivate high-end leaders, realize the complementary and win-win cooperation, and provide the core talents for the innovation and driving development of the province.

\subsection{Strengthening the Deep Cooperation of Industry-University-Research}

Guangdong Province shall focus on scientific and technological reform, make full use of the superior resources of Sun Yat-sen University, South China University of Technology, and other well-known enterprises, such as Tencent, Huawei and so on to deepen the cooperation between the industry-universityresearch of provincial departments and institutes, strengthen the construction of technological innovation system, construct a technological innovation system with enterprises as the main body, market as the guide, and combine the industry-university-research, and guide the relevant innovation elements to gather to the enterprises. As a model of national cooperation, Guangdong Province is worth learning from other provinces and cities in China. Other provinces and cities in China shall actively cooperate with the famous universities and scientific 
research institutes in their own province, and vigorously introduce the superior innovative resources and take the way of opening up and innovating. Continue to explore the "production" as the leading new industry-university-research entity management operation mechanism, so that other provinces and cities in China have made tangible contributions to the restructuring of the product structure of enterprises in the province and accelerating the industrialization of high and new technology and the transformation of traditional industries into high and new technologies.

\section{Conclusion}

Under the guidance of national strategy and local policies, a number of unique and innovative models for the development of provinces have emerged in China. For example, the Government-led Innovation Model in Jiangsu Province, the Innovation Model in science and technology in Zhejiang Province, Innovation Mode of Guangdong's Multi-dimensional Linkage, Innovation Mode of training and introducing High-end talents in Shaanxi, Innovation Mode of knowledge leading in Hubei, and Innovation Mode of Shandong Technology Service, etc. Through the analysis, we can see that the construction of domestic innovation-type provinces generally adheres to the strategy of driving development through innovation, creating a favorable policy environment, focusing on the development of innovative industries, accelerating the pooling of talents, and strengthening the cooperation among industry. These practices have many beneficial implications for the construction of innovation-type provinces in other provinces in China.

\section{Acknowledgements}

The research is financed by the Philosophy and Social Science Foundation of Anhui under Grant Nos. AHSKZ2016D07t, and he Natural Science Foundation of Anhui under Grant Nos. 1508085QG143.

\section{References}

Bo, J., Cao, J., \& Si, F. (2013). Analysis on the Construction Mode of Innovation-Oriented City. Commercial Age, 33, 20-21.

Chen, Z. (2009). The Enterprise Path of Innovation-Oriented City Construction-Analysis on the Independent Innovation Mode of Shenzhen Enterprises with Competitive Advantage. Journal of Nantong University (Social Sciences Edition), 4, 108-115.

Duan, J., Zhang, Z., \& Long, H. (2016). Innovation-Oriented City Development Patterns Analysis and Innovation Ability Evaluation-A Case Study of Shenzhen. 1, 58-63.

Gu, S., \& Ying, K. (2008). Discussion on Construction Fund Allocation Mode in the Background of the Innovation-Oriented City. Zhejiang Financial, 10, 33-34.

He, Y. (2007). An Analysis of the Elements and Models of the Innovation-Oriented City. Market Modernization, 8, 228-229.

Hu, T., \& Liu, Q. (2010). Construction Practice and Mode of Innovation-Oriented City. Journal of Administrative Colleges in Other Provinces and Cities of China, 4, 57-61. 
Jiang, X. (2010). Research on the Domestic Practice and Basic Mode of InnovationOriented City Construction. China Urban Economy, 10, 36-38.

Jiang, Y., \& Zheng, H. (2013). A Comparative Study on the Way and Mode of Innovation-Oriented City Construction-Take Guangzhou and Shenzhen as an Example. Technological Management Research, 14, 24-30.

Lan, X., \& Chen, J. (2015). Research on the Development Model of Innovation-Oriented City. Journal of Chongqing Second Normal University, 5, 24-28.

Lu, L. et al. (2008). Research on the Mode of Promoting International Scientific and Technological Cooperation in Innovation-Oriented City. Management of Scientific Research, S1, 75-79.

Peng, J. (2013). Research on the Mode of Science Popularization in Innovation-Oriented City (p. 96). Nanning: Guangxi University.

Shen, L., \& Wang, R. (2009). A Summary of the Types and Patterns of Conditions for the Construction of Innovation-Oriented City. Market Modernization, 14, 325-326.

Wu, S. (2014). Research on R \& D Model and Innovation Performance of InnovationOriented City Enterprises. Management of Scientific Research, 1, 33-40.

$\mathrm{Xu}$, A. (2013). Research on the Development Mode and Innovation-Oriented City Way (p. 200). Shijiazhuang: Hebei University of Technology.

$\mathrm{Xu}$, A. (2013). Study on the Evolution Process of Innovation-Oriented Development Model-Based on Niche Theory Perspective. Development and Research, 6, 30-35.

Yang, D. M., Zhao, L. M., \& Yan, L. Z. (2006). Innovative City: Conceptual Model and Development Pattern. Science of Science \& Management of $S \&$, 8, 97-101.

You, J. et al. (2011). Analysis on the Construction Mode of Innovation-Oriented CityTake Shanghai and Shenzhen as Examples. China Soft Science, 7, 82-92.

Zhang, G., \& Lin, C. (2006). International Comparison of the Innovation-Oriented City Construction Models-Take London, Boston, Singapore as an Example. In The Second China Symposium on Science and Technology Policy and Management and International Forum on Science and Technology Metrology (p. 8). Dalian. 